\title{
Dreaming during scientific papers: effects of added extrinsic material
}

\author{
RICHARD F HARVEY, MELVIN B SCHULLINGER, ALEXIS STASSINOPOULOS, ERICA WINKLE
}

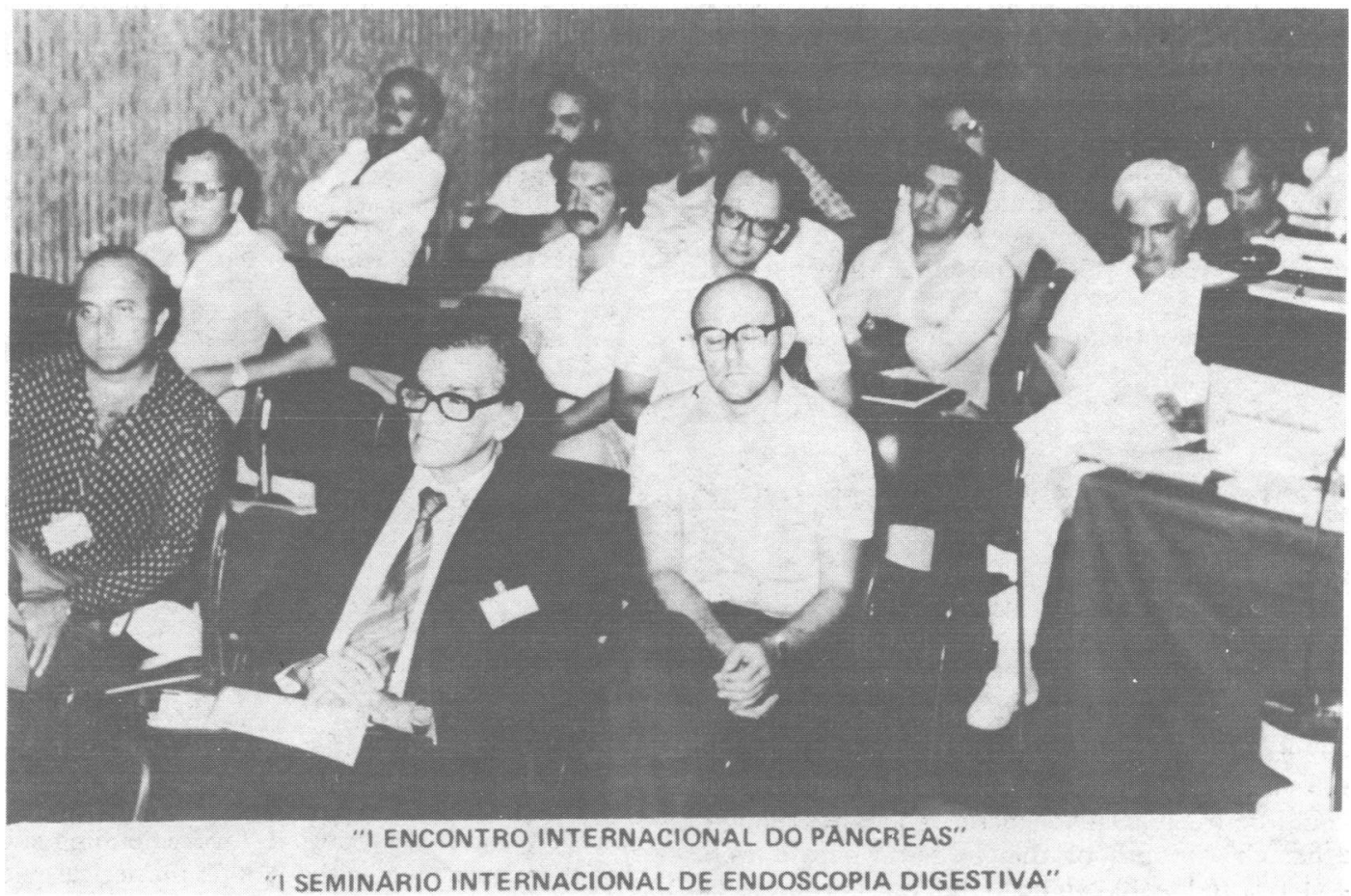

FIG 1-Typical audience sample (infrared picture) to show eye signs. Of 14 members of the audience in view, eyes are "normal" in three, "moving inappropriately" in one, "fixed and glassy" in two, "ptosis" in two, and "closed" in six.

As part of a continuing investigation into communicators' attitudes to teaching audit, one of us (MBS) has been exploring the mechanisms of retention of verbally transmitted material in a conventional stylised lecture setting. Preliminary studies suggested that little or none of the content of the lectures on a course given by one of us (MBS) was actually retained for more than 0.3 kiloseconds, and that recall was inversely proportional to the prevalence of sleep or dreaming among the audience, or both.

We have therefore carried out pilot studies to perfect our methodology, and then undertaken the present investigation to assess this phenomenon more fully.

\section{Pilot studies}

To determine the approximate prevalence of sleep among audiences at scientific meetings, a series of pilot studies was carried out at seven popular conference centres (Florence, Rio de Janeiro, Lausanne, Denver, Tokyo, Venice, and Reading).

\footnotetext{
Medical Communications Research Unit, Department of Medicine, Frenchay Hospital, Bristol BS16 1LE

RICHARD F HARVEY, MD, FRCP, consultant physician and director MELVIN B SCHULLINGER, honorary research associate

ALEXIS STASSINOPOULOS, MMRC travelling research person

ERICA WINKLE, BSC, honorary research assistan
}

Based on an item presented at the poster session of the Association of Physicians meeting held in Bristol in April 1983.
Travel and subsistence for these studies were kindly supported by grants HS426/A/21 (Social Investigations Fund); 7954/80 (Medical Meetings Research Council); and many solicited contributions from industry.

With infrared viewers when the lights were dim, the audience was scanned surreptitiously and the prevalence of sleep recorded. For this purpose we designed a stupor index based on the scoring system shown in table I.

TABLE I-Scoring system for stupor index

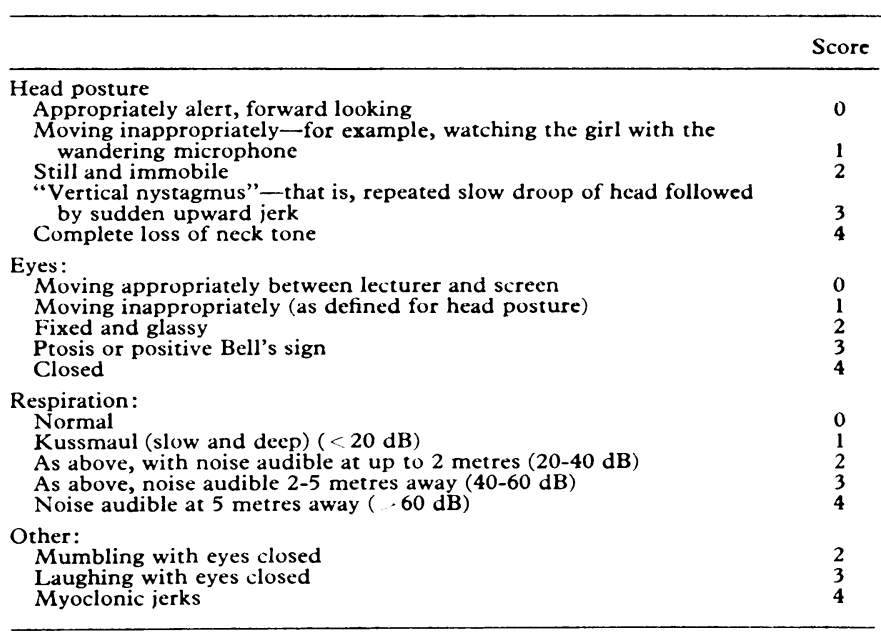
Interpretation of scores: $0=$ Unusually attentive (mainly rivals or coauthors);
$1-4=$ Normal; $5-6=$ Drifting; $7-9=$ Stuporose; $10-12=$ Asleep; $13-16=$ Asleep and socially unacceptable. 
With this system the pilot studies suggested an average prevalence of sleep of up to $40 \%$ (see fig 1 ). Although eye signs proved an excellent index of stupor or sleep, head posture and respiration or other signs were less reliable. Because of this we have in the present study used electroencephalography as a more accurate measurement of sleep than the stupor index.

During these pilot studies various factors were found to influence both the mean stupor index and dream rate in an unpredictable manner (see table II). For the purposes of this study all these factors were therefore excluded in the definitive investigation described below.

\section{Definitive study}

\section{METHODS}

\section{Lecturers}

By a process of informal consultation 12 male lecturers were selected who were known habitually to present the same supposedly original material at multiple (at least four) separate scientific meetings. All agreed to do the same during the 1981-2 seasons, but with randomly allocated extraneous slides added to their usual material, the major inducement to collaborate being the understanding that they would be cited as coauthors on any abstracts, preliminary communications, papers, book chapters, or reviews arising out of the study.

TABLE II-Factors found in pilot studies to have a general effect on stupor index, so excluded in definitive study

\begin{tabular}{|c|c|c|}
\hline Stimulus & $\begin{array}{c}\text { General } \\
\text { audience } \\
\text { reaction }\end{array}$ & Maximum observed reaction \\
\hline $\begin{array}{l}\text { Wandering photographer in } \\
\text { the auditorium }\end{array}$ & Wary, watchful & $\begin{array}{l}\text { Look alert, keenly interested, as } \\
\text { camera pointed in general } \\
\text { direction of subject }\end{array}$ \\
\hline $\begin{array}{l}\text { Important message on } \\
\text { television monitors-for } \\
\text { example, "Dr Smith wanted } \\
\text { urgently" or "Will all } \\
\text { delegates check that they } \\
\text { have handed in their keys" }\end{array}$ & No reaction & No reaction \\
\hline $\begin{array}{l}\text { Trivial message on television } \\
\text { monitors - for example, } \\
\text { "All illegally parked cars } \\
\text { are about to be towed } \\
\text { away" }\end{array}$ & $\begin{array}{l}\text { Nervous } \\
\text { conversation }\end{array}$ & Mass exodus \\
\hline $\begin{array}{l}\text { Use of laser pointer by } \\
\text { speakers }\end{array}$ & Wary, watchful & $\begin{array}{l}\text { Duck for cover if laser pointed } \\
\text { towards audience }\end{array}$ \\
\hline $\begin{array}{l}\text { Speakers with ability below } \\
5 \text { th percentile-for example, } \\
\text { unable to find way on to } \\
\text { rostrum or to put on } \\
\text { microphone }\end{array}$ & Very attentive & $\begin{array}{l}\text { (a) Laughter } \\
\text { (b) Leave for early coffee, } \\
\text { pretending to notice urgent } \\
\text { message on television monitor }\end{array}$ \\
\hline Certain female speakers & Very attentive & $\begin{array}{l}\text { Extremely attentive* } \\
\text { (exceptionally) clapping during } \\
\text { presentation* } \\
\text { (very exceptionally) cries of } \\
\text { "encore," "bravo," etc* }\end{array}$ \\
\hline $\begin{array}{l}\text { Some words and phrases- } \\
\text { for example, "in } \\
\text { conclusion," "finally" }\end{array}$ & & $\begin{array}{l}\text { "Arousal response"-that is, } \\
\text { open eyes, sit up, replace pen, } \\
\text { check watch, read summary to } \\
\text { see what speaker has been } \\
\text { talking about }\end{array}$ \\
\hline
\end{tabular}

- Seen especially in certain Latin countries.

\section{Audiences}

During eight separate medical meetings in 1981-2 a representative sample of 276 medical staff volunteered for the study. Each attended at least three of the meetings. Frequency of sleep and of rapid eye movement (REM) sleep were assessed by continuous radioelectroencephalography, and recall of lecture content, sleep, dream content (if any), and overall enjoyment of the presentation were assessed by a questionnaire completed at the next convenient break for coffee or tea.

\section{Extraneous material}

A series of 12 randomly selected slides was graded into four groups, of three slides each, according to the interest they aroused (objectively measured by changes in heart rate and sweat secretion of 20 non-beta blocked subjects). These groups of three slides were graded as "very boring," "neutral," "interesting," and "very interesting" (A, B, C, and D respectively). On each of the four times the lecturer gave his paper (15 minutes' duration) a different group of three slides was interposed randomly between his normal slides. The paper was then delivered in the usual way. Two of the original slides (one "very boring" and one "very interesting") had to be withdrawn because of adverse audience reaction and were replaced by less extreme slides. The final selection, grouped as previously described, is shown in fig 2 .

\section{Results and discussion}

Lecturers reported no difficulties in introducing the three extraneous slides into a 15 minute presentation, and most felt that they had been "worked in" without anybody noticing. This impression seemed to be confirmed by the audiences, few of whom seemed aware of any unusually irrelevant material having been shown.

The effects on sleep frequency, dream frequency, recall of lecture content, and dream content are shown in fig 3 and table III. Perhaps the most striking finding was that sleep frequency and dream frequency were unrelated. Dreaming often took place without electroencephalographic evidence of REM sleep; we propose the term "day dream" to cover this. Sleep frequency was relatively constant, whatever grade of extraneous material was introduced. This may partly be explained by the rapid onset of sleep in many subjects (often by the second slide), who were thus unable actually to see the extraneous material and therefore were not influenced by it.

Recall of lecture content was also surprisingly constant, although the inclusion of grade D ("very interesting") slides seemed slightly to decrease recall while increasing dream frequency.

Overall enjoyment of the presentations increased greatly when slides of grade $\mathrm{C}$ or D were added, by $76 \%$ and $179 \%$ respectively on a global assessment (linear analog scale), despite poor recall of the actual content of the lecture.

TABLE III-Dream content expressed as percentage of all dreams recalled, and analysed by occupation of dreamer

\begin{tabular}{|c|c|c|c|c|c|c|c|c|}
\hline \multirow{2}{*}{ Topic } & \multicolumn{8}{|c|}{ Grades of staff } \\
\hline & Registrar & Senior registrar & Senior lecturer & NHS consultant & Reader & Professor & Emeritus professor & Mean \\
\hline $\begin{array}{l}\text { Medical politics and/or money } \\
\text { Food } \\
\text { Drink } \\
\text { Travel* } \\
\text { Bladder } \\
\text { Others } \dagger\end{array}$ & $\begin{array}{r}10 \\
50 \\
85 \\
5 \\
5 \\
90\end{array}$ & $\begin{array}{r}40 \\
50 \\
40 \\
10 \\
0 \\
80\end{array}$ & $\begin{array}{r}75 \\
60 \\
20 \\
65 \\
5 \\
75\end{array}$ & $\begin{array}{r}95 \\
65 \\
90 \\
75 \\
10 \\
100\end{array}$ & $\begin{array}{l}80 \\
50 \\
10 \\
80 \\
10 \\
60\end{array}$ & $\begin{array}{r}70 \\
75 \\
95 \\
95 \\
30 \\
100\end{array}$ & $\begin{array}{r}25 \\
75 \\
25 \\
50 \\
100 \\
100\end{array}$ & $\begin{array}{l}70 \\
55 \\
50 \\
45 \\
15 \\
\end{array}$ \\
\hline
\end{tabular}

*Included both foreign trips and calculating how to slip away from the meeting without being missed. tMost frequently quoted topics included: weather; cricket; sexual fantasy (mainly junior staff); bran; fishing; Wogan; Dallas; golf; and the problems of delivering an adequate
standard of health care to inner city areas. 

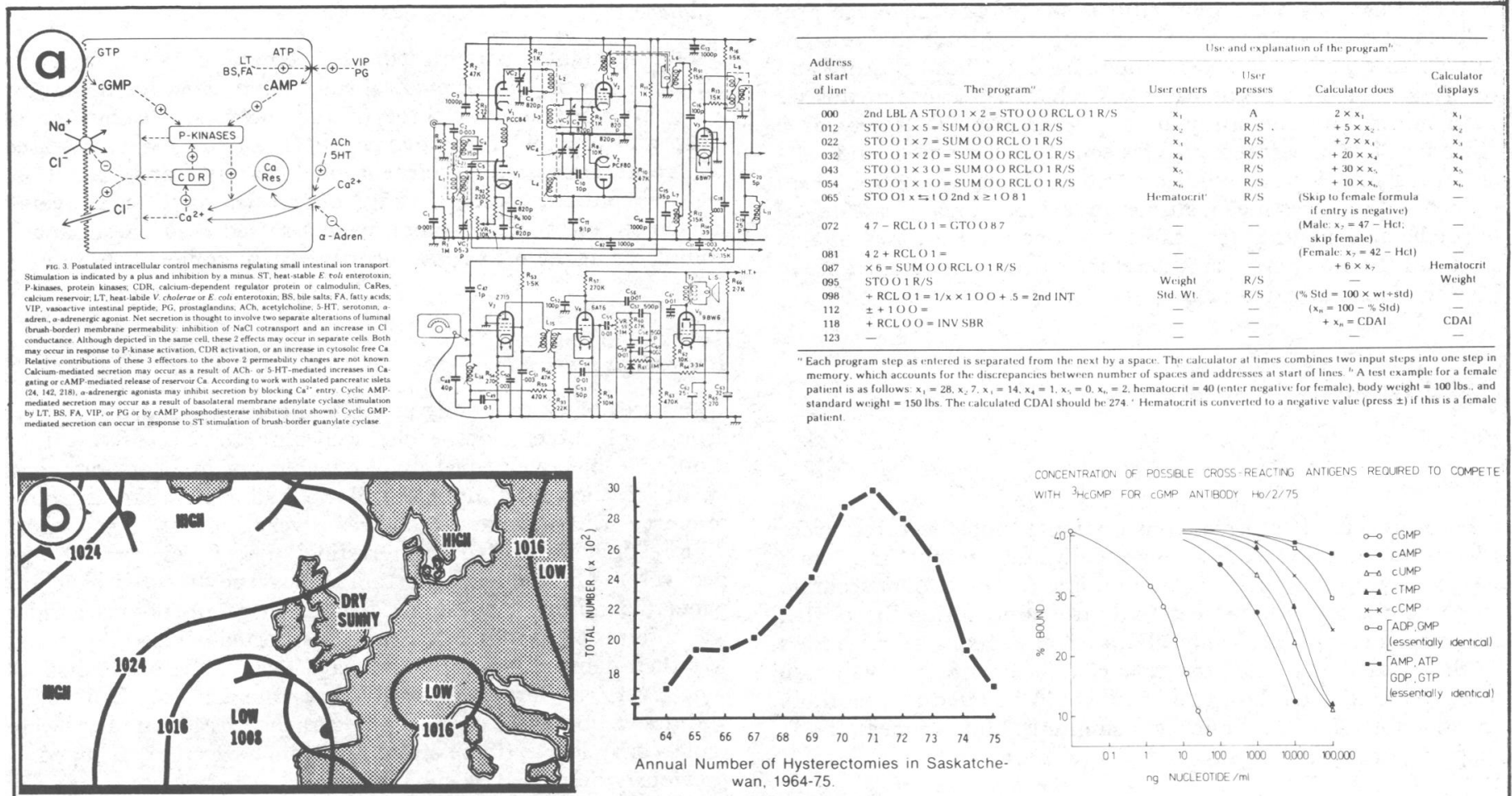

Annual Number of Hysterectomies in Saskatche-
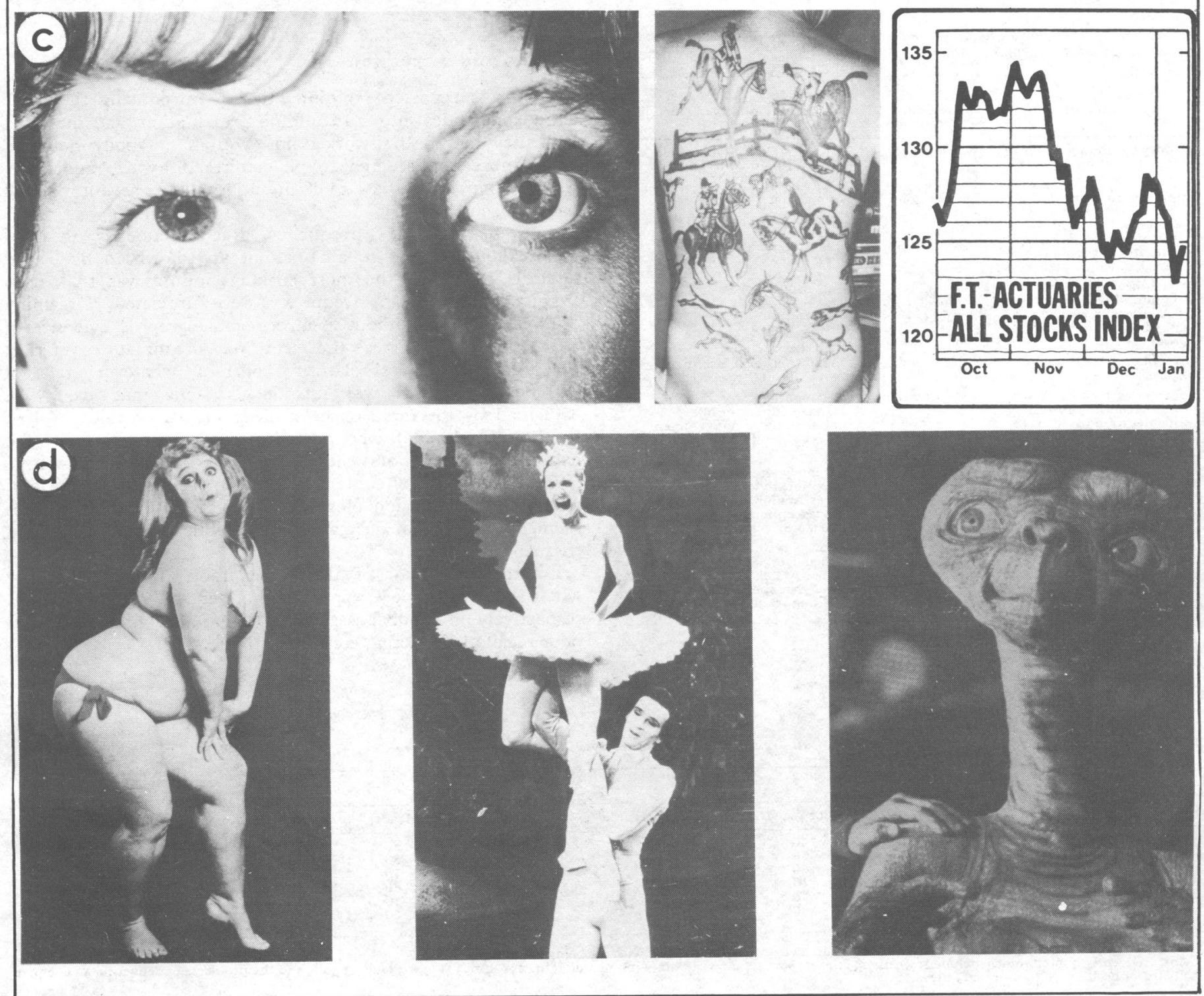

FIG 2-Extraneous material: group A, very boring; group B, neutral; group C, interesting; group D, very interesting. 

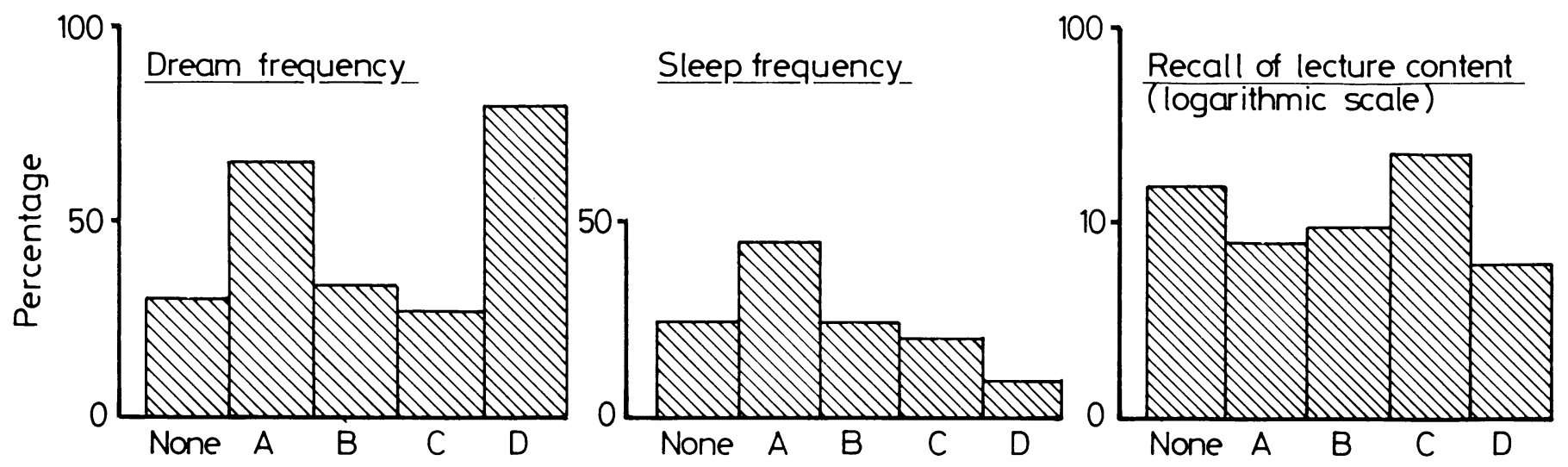

FIG 3-Effects of the different grades of extraneous material on dream and sleep frequency and recall of lecture content.

\section{Summary and conclusions}

During a series of presentations of scientific papers $40.6 \%$ of 276 subjects reported dreaming, but only $18 \cdot 1 \%$ actually fell asleep. The frequency of dreaming was significantly increased by the addition of either "very boring" or "very interesting" slides to the usual ones, but not by "neutral" slides. The recall of lecture content and the proportion of audience asleep were (surprisingly) not greatly affected by the addition of extraneous slides of any sort. On the other hand, adding "very interesting" slides greatly increases audience enjoyment.

I am very grateful to all those who helped in the preparation of this paper and of the poster on which it was based, particularly Simon Tutty and Peter Cox of the Department of Medical Illustration,
Frenchay Hospital. I thank Jennifer Harvey, Judy Seward, and Julia Flenley, who carried out the typing in secret, and Dr Alex Paton and Dr Stephen Lock for their helpful suggestions. Some of the illustrations and "extraneous material" came from Dr Janet Albano, $\mathrm{Mr}$ Roger Celestin, Dr Glaciomar Machado, Dr Francis Page, Dr Paul Serviour, and Dr Roger White. The pictures in fig 2 are reproduced by courtesy of the American Physiological Society, the New England fournal of Medicine, the Financial Times, the Sunday Times, Express Newspapers, Athena International, Steven Spielberg and Universal International Pictures, and the American Gastroenterological Association, and I am most grateful to them all.

We are also particularly indebted to the 12 lecturers who took part in the study. It has, unfortunately, not been possible to include them as coauthors. They have been unable to give their permission for this in time, owing to absence on speaking engagements abroad.

\title{
The critical attitude in medicine: the need for a new ethics
}

\author{
NEIL MCINTYRE, KARL POPPER
}

\begin{abstract}
"These standards of objective truth and criticism may teach him (the individual man) to try again and to think again; to challenge his own conclusions, and to use his imagination in trying to find whether and where his own conclusions are at fault. They may teach him to apply the method of trial and error in every field, and especially in science; and thus they may teach him how to learn from his mistakes, and how to search for them. These standards may help him to discover how little he knows and how much there is he does not know. They may help him to grow in knowledge, and also to realise that he is growing. They may help him to become aware of the fact that he owes his growth to other people's criticism and that reasonableness is readiness to listen to criticism."
\end{abstract}

KARL POPPER, 1978

Mistakes occur in medicine as in other walks of life. Their consequences may be trivial, but often they are serious, and they may be catastrophic. Some errors cannot be helped; others are avoidable, even culpable. Steps may be taken to correct errors but in

Royal Free Hospital School of Medicine, London NW3 2QG

NEIL MCINTYRE, MD, FRCP, professor of medicine

Penn, Buckinghamshire

SIR KARL POPPER, CH, PHD, FRS, philosopher many instances the mistake is irrevocable; the only benefit is the prevention of similar errors in future. Doctors are expected to profit from their experiences, and from their earliest days medical students are exhorted to learn from their mistakes. To learn only from one's own mistakes would be a slow and painful process and unnecessarily costly to one's patients. Experiences need to be pooled so that doctors may also learn from the errors of others. This requires a willingness to admit that one has erred and to discuss the factors that may have been responsible. It calls for a critical attitude to one's own work and to that of others.

Unfortunately medical students and doctors see little evidence of such openness around them. Gorowitz and MacIntyre wrote: "No species of fallibility is more important or less understood than fallibility in medical practice. The physician's propensity for damaging error is widely denied, perhaps because it is so intensely feared. ... Physicians and surgeons often flinch from even identifying error in clinical practice, let alone recording it, presumably because they themselves hold ... that error arises either from their or their colleagues' ignorance or ineptitude."1 But errors need to be recorded and to be analysed if we are to discover why they occurred and how they could have been prevented.

If errors are not to be repeated it is important that certain attitudes, deeply rooted in the profession, are overcome. 